\title{
Urinary catheter use in patients with hip fracture: Are current guidelines appropriate? A retrospective review
}

\author{
Sruthi Thomas, MD \\ Nicole Harris, BSc \\ Johanna Dobransky, MHK \\ George Grammatopoulos, MBBS \\ Kathleen Gartke, MD \\ Allan Liew, MD \\ Steven Papp, MD, MSc
}

Accepted January 7, 2021

\section{Correspondence to:}

S. Papp

Division of Orthopaedic Surgery

The Ottawa Hospital - Civic Campus

1053 Carling Ave

Ottawa ON K1Y 4E9

spapp@toh.ca

Cite as: Can J Surg 2021 November 25; 64(6). doi: 10.1503/cjs.014620

\begin{abstract}
Background: Guidelines for urinary catheterization in patients with hip fracture recommend limiting catheter use and using intermittent catheterization preferentially to avoid complications such as urinary tract infection (UTI) and postoperative urinary retention (POUR). We aimed to compare current practices to clinical guidelines, describe the incidence of POUR and UTI, and determine factors that increase the risk of these complications.
\end{abstract}

Methods: We retrospectively reviewed the charts of patients with hip fracture who presented to a single large tertiary care centre in southeastern Ontario between November 2015 and October 2017. Data collected included comorbidities, catheter use and length of stay. We compared catheter use to guidelines, and investigated the incidence of and risk factors for POUR and UTI.

Results: We reviewed the charts of 583 patients, of whom 450 (77.2\%) were treated with a catheter, primarily indwelling (416 [92.4\%]). Postoperative urinary retention developed in 98 patients $(16.8 \%)$; however, it did not affect length of stay $(p=0.2)$. Patients with indwelling catheters for more than 24 hours after surgery had a higher incidence of POUR than those who had their catheter removed before 24 hours $(65 / 330[19.7 \%]$ v. $10 / 98$ [10.2\%]) (odds ratio [OR] 2.2, 95\% confidence interval [CI] 1.06-4.38). A UTI developed postoperatively in 62 patients (10.6\%). Catheter use was associated with a 6.6-fold increased risk of UTI (OR 6.6, 95\% CI 2.03-21.4). Patients with indwelling catheters did not have a significantly higher incidence of UTI than those with intermittent catheterization $(57 / 416[13.7 \%]$ v. $2 / 34[5.9 \%])(p=0.2)$. Patients who developed a UTI had significantly longer catheter use than patients who $\operatorname{did} \operatorname{not}(p<0.002)$.

Conclusion: Indwelling catheters were used frequently, which suggests low compliance with clinical guidelines. Longer duration of catheter use led to higher rates of UTI and POUR. Further investigation of the reasons for the common use of indwelling rather than intermittent catheterization is needed.

Contexte : Les lignes directrices pour le cathétérisme vésical chez les patients ayant subi une fracture de la hanche préconisent de limiter la pose de sondes à demeure et d'opter plutôt pour le cathétérisme intermittent afin d'éviter les complications telles que l'infection urinaire (ou cystite) et la rétention urinaire postopératoire (RUPO). Nous avons voulu comparer les pratiques actuelles et les lignes directrices cliniques, établir l'incidence des cas de RUPO et d'infection urinaire et déterminer quels facteurs exacerbent le risque à l'égard de ces complications.

Méthodes : Nous avons procédé à une analyse rétrospective des dossiers de patients victimes d'une fracture de la hanche ayant consulté dans un grand centre hospitalier universitaire du Sud-Est de l'Ontario entre novembre 2015 et octobre 2017. Les données recueillies incluaient les comorbidités, l'utilisation de cathéters et la durée du séjour. Nous avons comparé le recours au cathéter par rapport aux lignes directrices et évalué l'incidence des cas de RUPO et d'infection urinaire, et les facteurs de risque.

Résultats : Nous avons analysé les dossiers de 583 patients, dont 450 (77,2\%) se sont fait poser un cathéter, principalement à demeure $(416[92,4 \%])$. La rétention urinaire postopératoire a affecté 98 patients $(16,8 \%)$; par contre, cela n'a pas influé sur la durée du séjour $(p=0,2)$. Les patients qui ont gardé leur sonde à demeure pendant plus de 24 heures après leur chirurgie ont présenté une incidence plus élevée de RUPO que ceux dont la sonde a été retirée en moins de 24 heures (65/330 [19,7\%] c. $10 / 98$ [10,2\%]) (rapport des cotes [RC] 2,2, intervalle de confiance [IC] de $95 \%$ 1.06-4.38). L'infection urinaire postopératoire a affecté 62 patients (10,6\%). Le recours au cathéter a été associé à une augmentation par un facteur de 6,6 du risque d'infection urinaire (RC 6,6, IC de $95 \%$ 2.03-21.4). Les patients à qui on avait posé 
une sonde à demeure n'ont pas présenté une incidence significativement plus élevée d'infection urinaire comparativement aux patients soumis à un cathétérisme intermittent $(57 / 416[13,7 \%]$ c. $2 / 34[5,9 \%])(p=0,2)$. Les patients qui ont présenté une infection urinaire ont gardé leur sonde significativement plus longtemps que les autres patients $(p<0,002)$.

Conclusion : Les sondes à demeure ont été utilisées souvent, ce qui n'est pas conforme aux lignes directrices cliniques. Une sonde portée plus longtemps a entraîné une hausse des taux d'infection urinaire et de RUPO. Il faudra explorer les raisons de l'utilisation répandue des cathéters à demeure plutôt qu'intermittents.

H ip fractures are a major cause of disability, morbidity and mortality. ${ }^{1-3}$ Most patients present with multiple comorbidities, which contributes to an increased risk of postoperative complications. ${ }^{4}$ Two common postoperative complications in this population are postoperative urinary retention (POUR) and urinary tract infection (UTI). These complications are detrimental to the patient and costly to health care systems. ${ }^{5,6}$

The reported prevalence of POUR - the inability to void in the presence of a full bladder - in patients with hip fracture is $20 \%-56 \% .^{7-9}$ Acutely, this can lead to impaired renal glomerular and tubular function. ${ }^{10}$ Chronic POUR can lead to hydronephrosis, pyelonephritis, renal insufficiency, bacteriuria and urinary incontinence. ${ }^{11}$ Some of the presenting signs and symptoms of these complications include discomfort, pain, acute confusion and delirium. ${ }^{12,13}$ Factors such as age, gender, multiple comorbidities and duration of surgery can influence the development of POUR. ${ }^{13-16}$

Patients with POUR are treated with urinary catheterization. Evidence-based interventions involving early recognition and appropriate management of POUR can decrease the risk of complications, especially in patients older than 65 years. ${ }^{12,17}$ This improves patient satisfaction and also reduces hospital costs by decreasing necessary interventions and overall length of stay. ${ }^{18}$ Although catheterization is the treatment for POUR, prolonged catheter use can lead to bladder dysfunction, and, therefore, catheterization itself can lead to urine retention after catheter removal. ${ }^{15}$ Urethral catheterization can also lead to development of a UTI, and can cause urethral trauma, bleeding and stricture, and decreased patient comfort. Indwelling catheterization is associated with an estimated $80 \%$ of hospital-acquired UTIs. ${ }^{19}$ This most common complication - "simple UTI" - can easily progress to urosepsis and septicemia. ${ }^{20}$ For each day that a catheter remains in the bladder, the incidence of bacteriuria increases by $3 \%-7 \% .^{21}$

Given these known issues, catheterization should be kept to a minimum. The US Centers for Disease Control and Prevention Healthcare Infection Control Practices Advisory Committee recommends avoiding indwelling catheters whenever possible and favours intermittent catheterization whenever catheterization is deemed neces- sary. ${ }^{22}$ A similar guideline was put forward in the Ontario Quality-Based Procedures Clinical Handbook for Hip Fracture $^{23}$ and the National Hip Fracture Toolkit, ${ }^{24}$ with recommendations to minimize catheterization and to use intermittent catheterization. The Healthcare Infection Control Practices Advisory Committee ${ }^{22}$ and the National Association of Orthopaedic Nurses ${ }^{25}$ recommend removal of the catheter within the first 24 hours postoperatively. The Quality-Based Procedures Clinical Handbook for Hip Fracture does not present a definitive timeline; however, it recommends catheter removal as soon as possible. At our institution, standard of care includes limiting use of catheters if patients can void on their own, using intermittent catheterization rather than indwelling catheters whenever possible, and minimizing indwelling catheter use to 24 hours postoperatively if needed.

In this study, we aimed to compare current practices in catheter use to clinical guidelines at a large tertiary care centre, describe the incidence of POUR and UTI in patients with hip fracture, and determine factors that increase the risk of POUR and UTI.

\section{Methods}

\section{Design and setting}

We performed a retrospective review of the charts of a random sample of patients with hip fractures (femoral neck, intertrochanteric or subtrochanteric) who presented to a single large tertiary care centre in southeastern Ontario between November 2015 and October 2017. Patients with incomplete medical records were excluded from the study. Age, sex, comorbidities, fracture pattern, surgical procedure, length of stay, catheter use, and the development of POUR and UTI were collected from medical and nursing records.

For a representative sample with a margin of error of $3 \%$ and $\alpha$ of $5 \%$, we required a minimum sample size of 579 .

\section{Established protocols}

As per the order sets at our institution, appropriate criteria for indwelling catheter use include the following: the 
patient shows acute urine retention; the patient requires accurate measurement of intake and output; the patient has an epidural catheter in situ, or the patient is incontinent and the catheter is in place to assist with the healing of open sacral wounds; prolonged immobilization secondary to an unstable thoracic or lumbar spine fracture or an unstable pelvic fracture; need for continuous bladder irrigation; the patient needs a urinary catheter for a prolonged period or has a suprapubic catheter; or to facilitate end-of-life care. Indwelling catheters can also be maintained if inserted by a urologist or required for selected surgical procedures, including urologic, genitourinary or colorectal. Reassessment of the need for catheterization every shift and catheter removal are required unless these criteria are met.

After catheter removal, the patient must be assessed within 6 hours to ensure appropriate voiding. If the patient is unable to void or has abdominal fullness or discomfort, a postvoid residual volume assessment is recommended; if the postvoid residual volume is greater than $400 \mathrm{~mL}$, intermittent catheterization every 6 hours for 24 hours is advised. The physician is informed if POUR persists for more than 24 hours.

\section{Outcomes}

We defined POUR as a bladder scan volume of greater than $400 \mathrm{~mL}$. On our current clinical pathway, a bladder scan is done if a patient has not voided by 6 hours postoperatively. ${ }^{26,27}$ The presence of a UTI was determined based on clinical presentation and urinalysis, and was documented in the clinical chart. Guidelines for clinical use were drawn from the Healthcare Infection Control Practices Advisory Committee guidelines for prevention of catheter-associated UTIs, the National Association of Orthopaedic Nurses guidelines for hip fracture management and the Ontario Quality-Based Procedures Clinical Handbook for Hip Fracture. 22,23,25 Specifically, we evaluated for length of catheterization less than 24 hours, type of catheterization and postvoid residual volume assessment. In addition, we evaluated for POUR and UTI, and examined predictors of their development.

\section{Statistical analysis}

We evaluated the data initially using basic descriptive statistics, followed by an independent sample $t$ test and $\chi^{2}$ test for continuous and dichotomous variables, respectively, to determine differences in demographic and clinical characteristics. We used a stepwise logistic regression model with a backward elimination approach to examine the predictors of POUR and UTI. All analyses were performed with SPSS Statistics version 26 (IBM Corp.). Significance was set at a $p$ value of less than 0.05 .

\section{Table 1. Baseline characteristics of patients with hip fracture}

\begin{tabular}{|lc|}
\hline Characteristic & \begin{tabular}{c} 
No. $\begin{array}{c}\%) \text { of patients* } \\
n=583\end{array}$ \\
\hline Age, mean \pm SD, $y r$
\end{tabular} \\
\hline Sex & $77.3 \pm 16.7$ \\
\hline Male & $197(33.8)$ \\
\hline Female & $386(66.2)$ \\
\hline $\begin{array}{l}\text { Time from consultation to arrival in operating } \\
\text { room, mean } \pm \text { SD, } h\end{array}$ & $32.9 \pm 28.4$ \\
\hline Length of stay, mean \pm SD, $d$ & $12.1 \pm 27.5$ \\
\hline Fracture type & \\
\hline Femoral neck & $257(44.1)$ \\
\hline Intertrochanteric & $315(54.0)$ \\
\hline Subtrochanteric & $1(0.2)$ \\
\hline Other & $10(1.7)$ \\
\hline Procedure & $239(41.0)$ \\
\hline Arthroplasty & $93(16.0)$ \\
\hline Dynamic hip screw & $223(38.2)$ \\
\hline Nail & $18(3.1)$ \\
\hline Cannulated screws & $10(1.7)$ \\
\hline Other & $8(1.4)$ \\
\hline Medical history & $24(4.1)$ \\
\hline Incontinence & $13(2.2)$ \\
\hline Benign prostatic hyperplasia & $10(1.7)$ \\
\hline Cancer of bladder or prostate & $101(17.3)$ \\
\hline UTI & $58(9.9)$ \\
\hline Diabetes mellitus & \\
\hline Kidney disease & \\
\hline $\begin{array}{l}\text { UTI = urinary tract infection; SD = standard deviation. } \\
{ }^{*} \text { Except where noted otherwise. }\end{array}$ \\
\hline
\end{tabular}

\section{Results}

Between November 2015 and October 2017, 1260 patients were treated for hip fracture. We selected a random sample of 614 patients, of whom 31 were excluded ( 21 because of miscoding [e.g., distal femur open reduction and internal fixation], 9 because of incomplete voiding records, and 1 patient requested that their protected health information be locked). The cohort thus consisted of 583 patients, 386 women $(66.2 \%)$ and 197 men $(33.8 \%)$ with a mean age of 77.3 (range 18-102) years (Table 1).

A total of 253 patients (43.4\%) had postoperative incontinence. Fifty patients $(8.6 \%)$ were readmitted within 30 days.

A catheter was used in 450 patients $(77.2 \%)$ during their hospital stay. The majority of patients (286 [63.6\%]) underwent catheter placement preoperatively (in the emergency department $[n=241]$ or on the ward [ $n=45]$ ), and the remainder underwent catheter insertion intra- or postoperatively (Table 2). The indication for catheter use was rarely documented. Indwelling catheters were used most commonly (416 patients [92.4\%]). Of the patients treated with an indwelling catheter, $328(78.8 \%)$ had the catheter in place for more than 24 hours, 65 (15.6\%) required catheter reinsertion after removal, and 66 


Table 2. Postadmission catheter practices
\begin{tabular}{|lc|} 
Variable & $\begin{array}{c}\text { No. }(\%) \text { of patients } \\
n=450\end{array}$ \\
\hline First insertion of catheter & $241(53.6)$ \\
\hline Emergency department & $45(10.0)$ \\
\hline Preoperatively & $164(36.4)$ \\
\hline Postoperatively & $34(7.6)$ \\
\hline Catheter type & $416(92.4)$ \\
\hline Intermittent & $328(72.9)$ \\
\hline Indwelling & $65(14.4)$ \\
\hline Catheter in place $>24$ h postoperatively & $26(40.0)$ \\
\hline Catheter reinserted after removal & $66(14.7)$ \\
\hline Owing to POUR & \\
\hline Catheter in place at discharge & POUR $=$ postoperative urinary retention. \\
\hline
\end{tabular}

\begin{tabular}{|lc|}
\hline $\begin{array}{l}\text { Table 3. Predictors of postoperative urinary retention } \\
\text { Variable }\end{array}$ & OR $(95 \% \mathrm{Cl})$ \\
\hline Age & $1.003(0.980-1.027)$ \\
\hline Sex & $0.563(0.296-1.069)$ \\
\hline $\begin{array}{l}\text { Time from consultation to arrival in operating } \\
\text { room }\end{array}$ & $0.994(0.980-1.008)$ \\
\hline History of benign prostatic hyperplasia & $1.827(0.548-6.098)$ \\
\hline History of cancer of bladder or prostate & $0.000(-)$ \\
\hline History of UTI & $0.613(0.072-5.226)$ \\
\hline Diabetes mellitus & $0.740(0.362-1.513)$ \\
\hline Kidney disease & $2.010(0.895-4.511)$ \\
\hline Postoperative incontinence & $1.942(1.093-3.452)$ \\
\hline Postoperative UTI & $1.670(0.794-3.510)$ \\
\hline Catheter in place $>24 \mathrm{~h}$ postoperatively & $1.960(0.936-4.103)$ \\
\hline Cl = confidence interval; OR = odds ratio; UTI = urinary tract infection. \\
\hline
\end{tabular}

(15.9\%) were discharged with a catheter. The mean length of catheter use was 4.7 (standard deviation [SD] 6.5) days (range 0-69d).

\section{Incidence and predictors of postoperative urinary retention}

Postoperative urinary retention developed in 98 patients (16.8\%). Development of POUR did not affect length of stay $(p=0.2)$. Seventy-five patients developed POUR after catheter removal; patients who had an indwelling catheter for more than 24 hours after their surgery had a significantly higher incidence of POUR than those who had their catheter removed before 24 hours $(65 / 330$ [19.7\%] v. 10/98 [10.2\%]) (odds ratio [OR] 2.2, 95\% confidence interval [CI] 1.06-4.38). After other variables were controlled for, the only statistically significant predictor of POUR was postoperative incontinence (OR 1.942, 95\% CI 1.093-3.452) (Table 3). Having a catheter in place for more than 24 hours almost reached statistical significance (OR 1.960, 95\% CI 0.936-4.103).
Table 4. Predictors of postoperative urinary tract infection

\begin{tabular}{|lc|}
\hline Variable & OR $(95 \% \mathrm{Cl})$ \\
\hline Age & $1.028(0.996-1.060)$ \\
\hline Sex & $1.005(0.465-2.168)$ \\
\hline $\begin{array}{l}\text { Time from consultation to arrival in operating } \\
\text { room }\end{array}$ & $1.019(1.007-1.031)$ \\
\hline History of benign prostatic hyperplasia & $1.132(0.269-4.764)$ \\
\hline History of bladder or prostate cancer & $1.360(0.174-10.645)$ \\
\hline History of UTI & $0.516(0.059-4.549)$ \\
\hline Diabetes mellitus & $1.655(0.797-3.436)$ \\
\hline Kidney disease & $0.867(0.322-2.337)$ \\
\hline Postoperative incontinence & $1.673(0.874-3.199)$ \\
\hline Catheter in place $>24$ h postoperatively & $1.770(0.517-2.424)$ \\
\hline POUR & $1.120(0.849-3.692)$ \\
\hline $\begin{array}{l}\text { Cl = confidence interval; OR = odds ratio; POUR = postoperative urinary retention; UTI } \\
\text { urinary tract infection. }\end{array}$
\end{tabular}

\section{Incidence and predictors of hospital-acquired urinary tract infection}

A UTI developed postoperatively in 62 patients (10.6\%). The use of a catheter was associated with a 6.6 -fold increased risk of UTI (OR 6.6, 95\% CI 2.03-21.4). Patients with indwelling catheters did not have a significantly higher incidence of UTI than those with intermittent catheterization $(57 / 416$ [13.7\%] v. $2 / 34$ [5.9\%]) $(p=$ 0.2 ). Patients who developed a UTI had significantly longer catheter use than those who did not develop a UTI (7.9 [SD 13.8] d v. 3.6 [SD 3.11] d) ( $p<0.002)$. After other variables were controlled for, longer time from consultation to arrival in the operating room was a significant predictor of postoperative UTI (OR 1.019, 95\% CI 1.0071.031) (Table 4).

\section{Discussion}

In our population of patients with hip fracture who presented to a large tertiary care centre, $77.2 \%$ had a catheter placed during their hospital stay, of whom $92.4 \%$ received indwelling catheters. Postoperative urinary retention developed in $16.8 \%$ of patients, and a hospital-acquired UTI in $10.6 \%$. The only statistically significant predictor of POUR was postoperative incontinence, and longer time from consultation to arrival in the operating room was a significant predictor of postoperative UTI.

The current guidelines for catheter use in patients with hip fracture in our region are limited. There is a lack of guidance surrounding when or how to use catheters in these patients. In addition, there is no reference to the use of ultrasonographic screening for POUR. The Ontario Quality-Based Procedures Clinical Handbook for Hip Fracture recommends intermittent catheterization over indwelling catheters in patients with hip fracture. ${ }^{23}$ In contrast, the National Association of Orthopaedic Nurses recommends the use of indwelling urinary catheters as appropriate in 
patients with hip fracture who are unable to move or roll; are hemodynamically unstable; have a stage 3 or 4 sacral ulcer, acute neurogenic bladder, bladder outlet obstruction, complex other fractures or a history of chronic indwelling catheter use; or require comfort care only. ${ }^{25}$

A critical review of the literature suggests that these regional recommendations may be drawn from guidelines for the average medical patient and not our specific population: patients with hip fracture. For example, a metaanalysis by Zhang and colleagues ${ }^{28}$ showed that, in patients who underwent hip arthroplasty (a group similar to ours), indwelling catheterization was superior to intermittent catheterization at preventing POUR. A randomized trial in patients with hip fracture showed no difference in the frequency of UTI or POUR when comparing indwelling to intermittent catheterization. ${ }^{29}$ Patients treated with intermittent catheterization returned to normal urinary function (defined by complete bladder emptying) earlier than those treated with an indwelling catheter. In a randomized trial of both patients undergoing elective hip surgery and those with hip fracture, Nyman and colleagues ${ }^{30}$ found no increased frequency of UTI in either group. They stated that both intermittent and indwelling catheterization have their advantages and disadvantages in this population.

When indwelling catheters are used, they should be removed as soon as possible or, at a minimum, their use should be reassessed within 24 hours postoperatively.22,25 Our rates of catheterization (77.2\%) and use of indwelling catheters $(92.4 \%)$ are clearly a departure from the provincial guidelines. ${ }^{23,25} \mathrm{We}$ are not sure why this occurred, since our hospital hip fracture care pathway and order set follow these provincial guidelines closely. Owing to the retrospective nature of our study, we were unable to ascertain the reason for deviation from the written orders on a regular basis. Similarly, in the United Kingdom, Kamdar and colleagues ${ }^{31}$ found that $78 \%$ of patients with hip fracture at their institution received an indwelling catheter. There was a documented reason for catheterization in only one-third of cases. Those authors stated that effective documentation needs to explain why the indwelling option was chosen.

The prevalence of POUR at our centre, $16.8 \%$, is similar to that in other studies. ${ }^{24,32} \mathrm{We}$ were unable to reliably assess the impact of catheter type on development of POUR because of the retrospective nature of the study and because intermittent catheterization was used so infrequently.

The prevalence of hospital-acquired UTI in our study, $10.6 \%$, was lower than expected. ${ }^{33,34}$ The incidence of hospital-acquired UTI was independent of the type of urinary catheter used. However, in keeping with other studies, ${ }^{14,35}$ increased duration of catheterization increased the risk of UTI. Although a clear time cut-off was not evident in this study, minimizing the overall catheterization duration would be important in decreasing the incidence of postoperative UTI. In addition, increased catheterization duration (specifically $>24 \mathrm{~h}$ ) increased the risk of POUR. In a randomized trial, stop orders were effective in decreasing the number of "unnecessary" catheter days ${ }^{36}$ and are now a part of the order set at our institution.

In clinical practice, there may be a role for both intermittent and indwelling urinary catheterization in hip care. It is evident from our findings that the guidelines around hip fracture and catheter management had yet to translate to bedside care effectively. Thus, education of medical and nursing staff is key, especially in the emergency department, as this is often when patients with hip fracture receive a catheter. In addition, admission order sets should be changed to require regular assessment and automatic stop dates. Finally, patient-specific factors such as duration of surgery, patient preference and comorbidities should be considered in deciding which treatment option is most appropriate.

The Ontario Quality-Based Procedures Clinical Handbook for Hip Fracture guidelines recommend minimizing time to surgery, based on data from Health Quality Ontario's Rapid Review: Optimal Timing of Hip Fracture Surgery, ${ }^{37}$ as well as the National Hip Fracture Toolkit. ${ }^{24}$ A systematic review by Klestil and colleagues ${ }^{38}$ that included data for 31242 patients showed that minimizing time to surgery was associated with decreased odds of general complications including UTI. Similarly, in our population, increased time to surgery was associated with increased risk of UTI. This supports the recommendations for early surgery.

\section{Limitations}

There are limitations inherent to this retrospective chart review, including poor documentation of the indications for catheter insertion. In addition, the low number of patients treated with intermittent catheterization led to difficult statistical interpretation when comparing the 2 types of catheters.

\section{Conclusion}

Our data show that, in our region, most patients with hip fracture are managed with indwelling urinary catheters despite guideline recommendations to the contrary. However, our rates of POUR and UTI were not higher than expected. The reasons why our centre and others deviate from these guidelines are unclear and need further investigation. The guidelines themselves may also need to be reassessed in this specific patient population. A prospective database would lead to higher-quality, more complete data and provide an opportunity to assess patient satisfaction with their treatment in terms of catheter use. 
Affiliation: From the Division of Orthopaedic Surgery, University of Ottawa, The Ottawa Hospital, Ottawa, Ont.

Competing interests: None declared.

Contributors: S. Thomas, N. Harris, K. Gartke and S. Papp designed the study. N. Harris, G. Grammatopoulos and S. Papp acquired the data, which J. Dobransky, K. Gartke, A. Liew and S. Papp analyzed. S. Thomas, N. Harris, J. Dobransky and S. Papp wrote the manuscript, which J. Dobransky, G. Grammatopoulos and A. Liew critically revised. All authors gave final approval of the article to be published.

Content licence: This is an Open Access article distributed in accordance with the terms of the Creative Commons Attribution (CC BYNC-ND 4.0) licence, which permits use, distribution and reproduction in any medium, provided that the original publication is properly cited, the use is noncommercial (i.e., research or educational use), and no modifications or adaptations are made. See: https://creativecommons. org/licenses/by-nc-nd/4.0/.

\section{References}

1. Liporace FA, Egol KA, Tejwani N, et al. What's new in hip fractures? Current concepts. Am 7 Orthop 2005;34:66-74.

2. Pioli G, Lauretani F, Davoli ML, et al. Older people with hip fracture and IADL disability require earlier surgery. 7 Gerontol A Biol Sci Med Sci 2012;67:1272-7.

3. LeBlanc KE, Muncie H, LeBlanc L. Hip fracture: diagnosis, treatment, and secondary prevention. Am Fam Physician 2014;89:945-51.

4. Menzies IB, Mendelson DA, Kates SL, et al. The impact of comorbidity on perioperative outcomes of hip fractures in a geriatric fracture model. Geriatr Orthop Surg Rehabil 2012;3:129-34.

5. Dodd AC, Bulka C, Jahangir A, et al. Predictors of 30-day mortality following hip or pelvis fractures. Orthop Traumatol Surg Res 2016; 102:707-10.

6. Horn SR, Liu TC, Horowitz JA, et al. Clinical impact and economic burden of hospital-acquired conditions following common surgical procedures. Spine 2018;43:E1358-63.

7. Johannson RM, Christensson L. Urinary retention in older patients in connection with hip fracture surgery. 7 Clin Nurs 2010;19:2110-6.

8. Pomfret I. Urinary catheters: selection, management and prevention of infection. Br 7 Community Nurs 2000;5:6-8.

9. Balderi T, Mistraletti G, D'Angelo E, et al. Incidence of postoperative urinary retention (POUR) after joint arthroplasty and management using ultrasound-guided bladder catheterization. Minerva Anestesiol 2011;77:1050-7.

10. Baldini G, Bagry H, Aprikian A, et al. Postoperative urinary retention: anesthetic and perioperative considerations. Anesthesiology 2009; 110:1139-57.

11. Gray $M$. Urinary retention: management in the acute care setting. Am 7 Nurs 2000;100:40-7.

12. Pavlin DJ, Rapp SE, Polissar NL, et al. Factors affecting discharge time in adult outpatients. Anesth Analg 1998;87:816-26.

13. Smith NK, Albazzaz MK. A prospective study of urinary retention and risk of death after proximal femoral fracture. Age Ageing 1996;25: 150-4.

14. Michelson JD, Lotke P, Steinberg M. Urinary-bladder management after total joint-replacement surgery. $N$ Engl 7 Med 1988;319:321-6.

15. Tobu S, Noguchi M, Hashikawa T, et al. Risk factors of postoperative urinary retention after hip surgery for femoral neck fracture in elderly women. Geriatr Gerontol Int 2013;14:636-9.

16. Wells DL, Saltmarche A. Voiding dysfunction in geriatric patients with hip fracture. Orthop Nurs 1986;5:25-8.

17. Pavlin DJ, Pavlin EG, Fitzgibbon DR, et al. Management of bladder function after outpatient surgery. Anesthesiology 1999;91:42-50.

18. Teng CH, Huang Y, Kuo B, et al. Application of portable ultrasound scanners in the measurement of post-void residual urine. 7 Nurs Res 2005;13:216-24.
19. Johansson RM, Malmvall B, Andersson-Gäre B, et al. Guidelines for preventing urinary retention and bladder damage during hospital care. 7 Clin Nurs 2012;22:347-55.

20. Newman DK. Internal and external urinary catheters: a primer for clinical practice. Ostomy Wound Manage 2008;54:18-35.

21. Lo E, Nicolle L, Classen D, et al. Strategies to prevent catheterassociated urinary tract infections in acute care hospitals. Infect Control Hosp Epidemiol 2014;35:464-79.

22. Gould CV, Umscheid CA, Agarwal RK, et al.; Healthcare Infection Control Practices Advisory Committee. Guidelines for prevention of catheter-associated urinary tract infections 2009. Infect Control Hosp Epidemiol 2010;31:319-26.

23. Health Quality Ontario; Ministry of Health and Long-Term Care. Quality-based procedures clinical handbook for hip fracture. Toronto: Health Quality Ontario; 2013. Available: http://www.hqontario.ca/ evidence/publications-and-ohtac-recommendations/clinical-handbooks (accessed 2019 July 17).

24. Waddell J, editor. National hip fracture toolkit. Bone and Joint Canada; 2011.

25. Schneider MA. Prevention of catheter-associated urinary tract infections in patients with hip fractures through education of nurses to specific catheter protocols. Orthop Nurs 2012;31:12-8.

26. Miller AG, Mckenzie J, Greenky M, et al. Spinal anesthesia: Should everyone receive a urinary catheter? 7 Bone Foint Surg Am 2013;95: 1498-503.

27. Huang Z, Ma J, Shen B, et al. General anesthesia: To catheterize or not? A prospective randomized controlled study of patients undergoing total knee arthroplasty. 7 Arthroplasty 2015;30:502-6.

28. Zhang $\mathrm{W}$, Liu $\mathrm{A}, \mathrm{Hu} \mathrm{D}$, et al. Indwelling versus intermittent urinary catheterization following total joint arthroplasty: a systematic review and meta-analysis. PLoS One 2015;10:e0130636.

29. Skelly JM, Guyatt G, Kalbfleisch R, et al. Management of urinary retention after surgical repair of hip fracture. CMAJ 1992;146: 1185-9.

30. Nyman MH, Gustafsson M, Langius-Eklöf A, et al. Intermittent versus indwelling urinary catheterisation in hip surgery patients: a randomised controlled trial with cost-effectiveness analysis. Int 7 Nurs Stud 2013;50:1589-98.

31. Kamdar A, Yahya A, Thangaraj L. Retrospective observational study of the incidence of short-term indwelling urinary catheters in elderly patients with neck of femur fractures. Geriatr Gerontol Int 2009;9: $131-4$.

32. Kort NP, Bemelmans Y, Vos R, et al. Low incidence of postoperative urinary retention with the use of a nurse-led bladder scan protocol after hip and knee arthroplasty: a retrospective cohort study. Eur $\mathcal{F}$ Orthop Surg Traumatol 2018;28:283-9.

33. van den brand IC, Castelein RM. Total joint arthroplasty and incidence of postoperative bacteriuria with an indwelling catheter or intermittent catheterization with one-dose antibiotic prophylaxis: a prospective randomized trial. 7 Arthroplasty 2001;16:850-5.

34. Corigliano A, Galasso O, Varano A, et al. Urinary tract infections after early removal of urinary catheter in total joint arthroplasty. Eur Rev Med Pharmacol Sci 2019;23:38-42.

35. Knight RM, Pellegrini VD. Bladder management after total joint arthroplasty. 7 Arthroplasty 1996;11:882-8.

36. Loeb M, Hunt D, O'Halloran K, et al. Stop orders to reduce inappropriate urinary catheterization in hospitalized patients: a randomized controlled trial. 7 Gen Intern Med 2008;23:816-20.

37. Brener S. Optimal timing for hip fracture surgery: a rapid review. Toronto: Health Quality Ontario; 2013. Available: http://www. hqontario.ca/evidence/publications-and-ohtac-Optimal timing for hip fracture surgery recommendations/rapid-reviews (accessed 2021 Nov. 12).

38. Klestil T, Röder C, Stotter C, et al. Impact of timing of surgery in elderly hip fracture patients: a systematic review and meta-analysis. Sci Rep 2018;8:13933. 